University of Nebraska - Lincoln

DigitalCommons@University of Nebraska - Lincoln

\title{
Effects of the HEET Garment in the Prevention of Hypothermia in a Porcine Model
}

\author{
Don Johnson \\ US Army Graduate Program in Anesthesia Nursing, arthur.johnson@amedd.army.mil \\ Brian Gegel \\ Brooke Army Medical Center \\ James Burgert \\ Brooke Army Medical Center \\ Geoffrey W, Duncklee \\ US Army Graduate Program in Anesthesia Nursing \\ Ricci R. Robinson \\ US Army Graduate Program in Anesthesia Nursing \\ See next page for additional authors
}

Follow this and additional works at: https://digitalcommons.unl.edu/usarmyresearch

Part of the Operations Research, Systems Engineering and Industrial Engineering Commons

Johnson, Don; Gegel, Brian; Burgert, James; Duncklee, Geoffrey W; Robinson, Ricci R.; Lewis, Eric J.; Crum, Paul M.; Kuhns, William; Moore, Daniel; O'Brien, Scott; Elliott, Joel; Washington, Jason; Boyle, John; and Seigler, Dale, "Effects of the HEET Garment in the Prevention of Hypothermia in a Porcine Model" (2010). US Army Research. 130.

https://digitalcommons.unl.edu/usarmyresearch/130

This Article is brought to you for free and open access by the U.S. Department of Defense at DigitalCommons@University of Nebraska - Lincoln. It has been accepted for inclusion in US Army Research by an authorized administrator of DigitalCommons@University of Nebraska - Lincoln. 


\section{Authors}

Don Johnson; Brian Gegel; James Burgert; Geoffrey W, Duncklee; Ricci R. Robinson; Eric J. Lewis; Paul M. Crum; William Kuhns; Daniel Moore; Scott O'Brien; Joel Elliott; Jason Washington; John Boyle; and Dale Seigler 


\title{
RESEARCH REVIEW
}

\section{Effects of the HEET Garment in the Prevention of Hypothermia in a Porcine Model}

\author{
Don Johnson, Ph.D., ${ }^{* 1}$ Brian Gegel, M.S.N., † James Burgert, M.S.N.A., $\dagger$ Geoffrey W. Duncklee, M.S.N.,* \\ Ricci R. Robison, M.S.N., ${ }^{*}$ Eric J. Lewis, M.S.N., ${ }^{*}$ Paul M. Crum, M.S.N., ${ }^{*}$ William Kuhns, M.S.N., ${ }^{*}$ \\ Daniel Moore, M.S.N., ${ }^{*}$ Scott O’Brien, M.S.N., ${ }^{*}$ Joel Elliott, M.S.N., ${ }^{*}$ Jason Washington, B.S.N., ${ }^{*}$ \\ John Boyle, M.S.N.,* and Dale Seigler, M.S.N.* \\ *US Army Graduate Program in Anesthesia, Fort Sam Houston, Texas; and †Brooke Army Medical Center, Fort Sam Houston, Texas
}

Submitted for publication May 19, 2009

Background. Hypothermia is a common battlefield trauma occurrence. This study compared the effectiveness of the hypothermia, environmental, exposure, and trauma (HEET) garment (Trident Industries, Beaufort, SC) with and without thermal inserts with a control group of two wool blankets in the prevention of hypothermia in a treated hypovolemic porcine model.

Materials and methods. Five female swine (Sus scrofa-Yorkshire cross) were assigned to each of three groups: HEET with thermal inserts $(n=5)$; HEET without thermal inserts $(n=5)$; or control $(n=5)$. After the animals were anesthetized and stabilized for $30 \mathrm{~min}$, the swine were hemorrhaged to a mean arterial pressure (MAP) of 30mm Hg, simulating a battlefield injury. Hetastarch $6 \%(500 \mathrm{~mL})$ was rapidly administered, simulating initial field resuscitation. One hour later, the animals' shed blood was reinfused, simulating transfusion at a field medical facility. The investigators moved the animal into a cooler set at $10^{\circ} \mathrm{C} \pm 0.5 \circ$. A pulmonary artery catheter was used to monitor core body temperature over a 6 -h period.

Results. A repeated measures ANOVA and Tukey's post hoc test were used to analyze the data. There was a significant difference between the groups. At the end of $6 \mathrm{~h}$, the mean core temperature for the HEET with inserts group was $32.69^{\circ} \mathrm{C} \pm 1.5$; the $\mathrm{HEET}$ without inserts, 31.02 $\mathrm{C} \pm 1.8$; and control, $34.78 \mathrm{C} \pm 1.2(P<0.05)$. While all groups became hypothermic, the wool blanket group was most effective in maintaining body temperature closer to normothermia.

\footnotetext{
${ }^{1}$ To whom correspondence and reprint requests should be addressed at US Army Graduate Program in Anesthesia, 7627 Lynn Ann, San Antonio, TX 78240. E-mail: Arthur.johnson@amedd. army.mil.
}

Conclusion. The HEET garments with and without heaters are ineffective in preventing hypothermia. Published by Elsevier Inc.

Key Words: hypothermia; aeromedic evacuation; combat care; hypothermic prevention.

\section{INTRODUCTION}

Currently, hypothermia prevention and treatment therapies are not standardized within the military services and vary between individual medical units to include US Army forward surgical teams and combat support hospitals. Therefore, thermal regulatory products, such as intravenous fluid warmers and blankets, including the hypothermia, environmental, exposure, and trauma (HEET) (Trident Industries, Beaufort, $\mathrm{SC})$, are used in an attempt to maintain normothermia in casualties. No studies have investigated the efficacy of this garment in the prevention of hypothermia.

The purpose of this study was to determine the effectiveness of the HEET garment with and without thermal inserts in the prevention of hypothermia in a treated hypovolemic porcine model. The following research question guided the study: Is there a significant difference in core body temperature of subjects exposed to a cold environment $\left(50^{\circ} \mathrm{F} / 10^{\circ} \mathrm{C}\right)$ over a 6 -h period, treated with the HEET with thermal inserts, HEET without thermal inserts, and a control group (2 wool blankets) in a resuscitated hypovolemic model? It was theorized the HEET garment would prevent the onset of hypothermia caused by the four common mechanisms of heat loss: convection, conduction, evaporation, and radiation. The garment is constructed of four layers of laminated aluminum polyethylene material, a precise 
vacuum deposition of pure aluminum, a reinforcing fabric called ASTROLAR, a layer of colored polyethylene film with a rip-stop nylon shell. The fabric weighs 3.42 ounces per yard. The garment is an air-insulated jacket with a reflectant inner layer, which is purported to retain and transfer heat back to the body by creating warm air pockets providing a barrier to cold. The garment has six pockets for air activated heat packs and can be used with or without warmers, such as HotHands (Heatmax, Dalton, GA). Two heat warmers can be inserted into each pocket of the HEET garment.

\section{METHODS}

Following review and approval by the Institutional Animal Care and Use Committee (IACUC), 15 female swine (Sus scrofa-Yorkshire cross) weighing between 55 and $64 \mathrm{~kg}$ (mean $=58.1, \mathrm{SD}=2.6$ ) were used for the study. The animals were premedicated with ketamine $(15-20 \mathrm{mg} / \mathrm{kg})$ and atropine $(0.04-0.4 \mathrm{mg} / \mathrm{kg})$ administered intramuscularly. Once sedated, the swine were intubated and mechanically ventilated. All animals were placed on two standard military wool blankets, folded over to achieve double thickness. During instrumentation, animals were maintained on isoflurane $(3.5 \%-5 \%)$ adjusted to maintain a surgical plane of anesthesia. The ambient temperature in the surgical suite was maintained at $70^{\circ} \mathrm{F}\left(21^{\circ} \mathrm{C}\right)$. Left carotid arterial, 2 central venous lines, and a pulmonary artery catheter (model number 834HF75; Edwards Life Sciences LLC, Irvine, CA) were inserted and connected to a GE Marquette monitor (Solar 8000; Medical Systems, Milwaukee, WI). Following line placement and stabilization of $30 \mathrm{~min}$, the animals were hemorrhaged via the femoral venous catheter line at a rate of approximately $4 \mathrm{~mL} / \mathrm{kg} / \mathrm{min}$ to a mean arterial pressure (MAP) of $30 \mathrm{~mm}$ $\mathrm{Hg}$ to simulate a battlefield injury. Following attainment of the target MAP of $30 \mathrm{~mm} \mathrm{Hg}$, animals were monitored without further intervention for $45 \mathrm{~min}$ to simulate the time to definitive initial care. After 45 min of untreated hypovolemic shock, $500 \mathrm{~mL}$ of room temperature $\left(21^{\circ} \mathrm{C}\right)$ hetastarch $6 \%$ (Hextend, Hospira, Inc., Lake Forest, IL) was rapidly administered, and monitoring was continued for an additional $60 \mathrm{~min}$ to simulate initial field resuscitation and evacuation from the battlefield. One hour after administration of hetastarch, the animals' shed blood $\left(37^{\circ} \mathrm{C}\right)$ was re-infused to simulate stabilization at a field medical facility prior to aeromedic evacuation. Throughout the preparatory, hemorrhage, and resuscitation phases of the study, the animal's core body temperature was maintained within $\pm 0.7^{\circ} \mathrm{C}$ of the preoperative measurement. To simulate transfer of the casualty in a cold aeromedic environment, the investigators moved the animals to a walk-in cooler. Temperature in the cooler was set at $10^{\circ} \mathrm{C} \pm 0.5^{\circ} \mathrm{C}$ as monitored by a calibrated wet-bulb globe thermometer (Portable Heat Stress Data Logger HS-3700; Metrosonics Inc., Rochester, NY). Airflow in the cooler was between 0.20 and $0.26 \mathrm{~m} / \mathrm{s}$ and was monitored by a thermoanemometer (Hot Wire Sensor model 407123; EXTECH Instruments, Waltham, MA) held 2 in. above the center of the animal. These thermal parameters were based on previous research in the C130 cargo aircraft, a widely used aircraft for aeromedic evacuation (Walsh, unpublished data).

Animals in all groups were positioned on top of a folded wool blanket, which served as padding, and placed on a standard NATO litter (Litter Folding Rigid Pole Aluminum Pole NSN 6530-00-783-7905) on stanchions. The standard aeromedic transport ventilator (Uni-vent Eagle 754; Impact Instrumentation Inc., West Caldwell, NJ) with an in-line heat moisture exchanger (HME) was used. All animals were covered with a double-layer cotton sheet to simulate military clothing.

Upon arrival in the cooler, anesthesia was converted to a continuous intravenous infusion of propofol ( $4-8 \mathrm{mg} / \mathrm{kg}$ ) and ketamine $2-3 \mathrm{mg} / \mathrm{kg} /$ $\mathrm{h}$ titrated to a surgical plane of anesthesia. To prevent the confounding effects of shivering, neuromuscular blockade was administered with pancuronium bromide $(0.10-0.15 \mathrm{mg} / \mathrm{kg} / \mathrm{h})$. Immediately upon arrival in the cooler, one of the three interventions was implemented and continued for the 6 -h study period. Animals were assigned to one of three treatment groups: HEET with heat inserts $(n=5)$, HEET without heat inserts $(n=5)$, or a control $(n=5)$ consisting of two folded wool blankets to achieve double thickness. All animals had one wool blanket underneath for padding and a double-layer sheet on top to simulate clothing. Only the control group had two wool blankets on top of the double-layer sheet.

For those subjects in the HEET with heat inserts, the investigators unwrapped the HotHands (Heatmax, Dalton, GA) packets, folded the packages and agitated back and forth to activate the chemical reaction to generate heat. The HotHands uses a fast oxidation process through the use of iron powder, water, salt, activated charcoal, and vermiculite. The product produces heat up to $180^{\circ} \mathrm{F}$ for duration up to $20 \mathrm{~h}$. This was performed 5 min before wrapping the animal with the HEET garment. A total of 12 HotHands warmers were placed in pockets located in the HEET garment. For both HEET groups, the garment was wrapped under the animal, then over the subject, and secured with Velcro. For the control group, two wool blankets were folded over the animal and tucked underneath the other wool blanket that served as padding. Core body temperature (pulmonary artery) readings were obtained every $15 \mathrm{~min}$. For both experimental groups, the HEET garment encircled the swine. Only the control group had two folded blankets placed over the animals.

A multivariate ANOVA was used to determine if there were any significant differences in baseline data. There were no significant difference in baseline core body temperature between the groups (HEET with inserts: mean $=37.32^{\circ} \mathrm{C} \pm 1.0$; HEET without inserts: mean $=36.98^{\circ} \mathrm{C} \pm 2$; control: mean $=37.42^{\circ} \mathrm{C} \pm 1.0$ ) immediately before entry into cooler $(P=0.689)$. There was also no significant difference in the amount of blood exsanguinated between groups to create a MAP of $30 \mathrm{mmHg}$ (HEET with inserts: mean $=1595 \pm 130 \mathrm{~mL}$; HEET without inserts: mean $=1608 \pm 148 \mathrm{~mL}$; control: mean= $1505 \pm 103 \mathrm{~mL})(P=0.497)$ indicating the groups were equivalent relative to these parameters at the beginning of the experimental phase of the study.

The means and standard deviations were calculated on the core body temperature measurements every hour for $6 \mathrm{~h}$ for each group. The results are presented as means \pm standard deviations. The alpha was set at 0.05 for all analyses. The data were analyzed using repeated ANOVA and a Tukey post-hoc test. Because Mauchly's test was significant $(P=0.000)$, the assumption of compound symmetry was not met. Therefore, the Greenhouse-Geisser corrected test was used and indicated that there were significant differences between the groups over time $(P=0.03)$.

Neither the HEET garment with or without inserts nor the wool blankets was effective in preventing hypothermia. After only $1 \mathrm{~h}$, there was a significant difference in the mean core temperature between the HEET without inserts group and control group $(P=0.032)$. After $3 \mathrm{~h}$ of exposure, both the HEET groups became hypothermic. After $4 \mathrm{~h}$ of exposure, all groups had hypothermia. At that hour, core temperature measurements for HEET garment with inserts: mean $=34.02^{\circ} \mathrm{C} \pm 1.1$; HEET garment without inserts: mean $=32.50^{\circ} \mathrm{C} \pm 1.7$; control: mean $=35.08^{\circ} \mathrm{C} \pm 1.1$. At the end of the $6 \mathrm{~h}$, the mean core temperature for the HEET with inserts group was $32.69^{\circ} \mathrm{C} \pm 1.5$; the HEET without inserts, $31.02^{\circ} \mathrm{C} \pm 1.8$; and the control, $34.78^{\circ} \mathrm{C} \pm 1.2$ (Table 1 ). Although all groups were hypothermic at the end of $6 \mathrm{~h}$, there was no significant difference between the HEET groups $(P=0.248)$ or the HEET with inserts and the control $(P=0.131)$. There was a significant difference between the HEET without inserts and the control $(P=0.007)$, indicating the control group was more effective in slowing the onset of hypothermia.

\section{DISCUSSION}

Up to $66 \%$ of trauma patients arriving in emergency departments have some degree of hypothermia 
TABLE 1

Comparison of Means and Standard Deviations and Significance of Core Body Temperature Over 6 Hours

\begin{tabular}{|c|c|c|c|c|c|c|}
\hline & \multirow[b]{2}{*}{$\begin{array}{l}\text { Group } 1 \text { HEET } \\
\text { with inserts }\end{array}$} & \multirow[b]{2}{*}{$\begin{array}{l}\text { Group } 2 \text { HEET } \\
\text { without inserts }\end{array}$} & \multirow[b]{2}{*}{$\begin{array}{c}\text { Group } \\
3 \text { Control }\end{array}$} & \multicolumn{3}{|c|}{ Post hoc analysis $P$ value } \\
\hline & & & & $\begin{array}{c}\text { Group } 1 \\
\text { versus group } 2\end{array}$ & $\begin{array}{c}\text { Group } 1 \\
\text { versus group } 3\end{array}$ & $\begin{array}{c}\text { Group } 2 \\
\text { versus group } 3\end{array}$ \\
\hline Baseline & $37.32 \pm 1.0$ & $36.98 \pm .20$ & $37.42 \pm 1.0$ & $P=(0.798)$ & $P=(0.980)$ & $P=(0.689)$ \\
\hline Hour 1 & $35.97 \pm 1.2$ & $35.64 \pm .32$ & $37.02 \pm 1.1$ & $P=(0.766)$ & $P=(0.108)$ & $P=(0.032)^{*}$ \\
\hline Hour 2 & $35.41 \pm 0.5$ & $34.48 \pm .85$ & $36.56 \pm 1.2$ & $P=(0.285)$ & $P=(0.167)$ & $P=(0.010)^{*}$ \\
\hline Hour 3 & $34.76 \pm 0.7$ & $33.28 \pm 1.3$ & $36.04 \pm 1.3$ & $P=(0.146)$ & $P=(0.230)$ & $P=(0.007)^{*}$ \\
\hline Hour 4 & $34.02 \pm 1.1$ & $32.50 \pm 1.7$ & $35.08 \pm 1.1$ & $P=(0.280)$ & $P=(0.500)$ & $P=(0.042)^{*}$ \\
\hline Hour 5 & $33.34 \pm 1.4$ & $31.88 \pm 2.0$ & $35.14 \pm 1.4$ & $P=(0.334)$ & $P=(0.209$ & $P=(0.017)^{*}$ \\
\hline Hour 6 & $32.69 \pm 1.5$ & $31.02 \pm 1.8$ & $34.78 \pm 1.2$ & $P=(0.248)$ & $P=(0.131)$ & $P=(0.007)^{*}$ \\
\hline
\end{tabular}

${ }^{*} P<0.05$ (control warmer than HEET without inserts).

(temperature $<96.8^{\circ} \mathrm{F}$ or $36^{\circ} \mathrm{C}$ ). Over $80 \%$ of nonsurviving trauma patients have a body temperature less than $34^{\circ} \mathrm{C}$. These data come from civilian casualty centers, where there is usually rapid transport of the patient in controlled thermal environments [1]. In military environments, hypothermia is commonly encountered during combat operations [2, 3]. The military faces challenges not encountered in civilian environments that may predispose patients to hypothermia. Specifically, military medical care during wartime and contingency operations are often conducted in austere conditions where cold environments are routine. For example, the average ground temperature in Iraq is $48-57^{\circ} \mathrm{F}$ $\left(9-14^{\circ} \mathrm{C}\right)$ during the fall/winter. In Afghanistan, it is 20 to $48^{\circ} \mathrm{F}\left(-6.6-8.8^{\circ} \mathrm{C}\right)$. However, hypothermia can occur when the ambient air temperature is high. Holcomb states hypothermia occurs with equal frequency in cold and warm environments. Anecdotal reports from surgeons deployed in support of Operations Iraqi Freedom/Enduring Freedom indicate the occurrence of hypothermia in casualties is common even when the temperature is well over $37^{\circ} \mathrm{C}$ [4].

Military medical care may occur in a variety of settings including deployable field hospitals and shelters of opportunity such as aircraft hangers. Additionally, casualties may be transported by helicopter where temperatures drop 3 to $5^{\circ} \mathrm{F}$ per 1000 feet of altitude. Unique to the military is the opening of doors and windows of the helicopter in flight so defensive weapons are ready to protect the aircraft. Also, rotary aeromedic evacuation flights may last up to $4 \mathrm{~h}$. This results in the exposure of the casualty to cold ambient air and convective winds of approximately $7.3-8.5 \mathrm{mph}$, accelerating the onset of hypothermia [Barazanji J., Personal Communication]. Additionally, casualties may be transported by fixed wing aeromedic evacuation (AE) aircraft that lack a regulated thermal environment.

Combat casualties are at further risk for hypothermia secondary to resuscitative measures, such as administration of large volumes of room temperature intravenous fluids and mechanical ventilation [5]. Furthermore, drugs administered to the casualty, such as sedatives, neuromuscular blockers, and opioids decrease the thermogenic effect of shivering $[6,7]$.

The military has made concerted efforts in hypothermia prevention. However, hypothermia continues to be a significant problem in the management of combat casualties. Arthurs and colleagues found $18 \%$ of combat casualties admitted to the 31st Combat Support Hospital $(\mathrm{CSH})$ were hypothermic (temperature $<36^{\circ} \mathrm{C}$ ). Furthermore, the presence of hypothermia was an independent predictor of perioperative outcome. Temperature less than $34^{\circ} \mathrm{C}$ was associated with nearly $100 \%$ mortality [8]. Other investigators have found hypothermia in trauma patients is associated with increased morbidity and mortality, and may cause coagulopathy, impaired wound healing, increased wound infection, prolonged recovery, and increased length of hospitalization $[9,10]$. Interventions to maintain normothermia improve patient outcomes [11].

Hypothermia research focuses primarily on the treatment of existing hypothermia and not on prevention, which was the focus of this research. Holcomb emphasizes prevention should be the focus rather than the treatment of hypothermia in combat operations. Prevention of hypothermia decreases mortality and morbidity, and may decrease time and resources allocated to actively rewarm hypothermic casualties. He summarizes prevention of hypothermia is much easier than treatment and prevents complications [12].

However, few studies have investigated prevention with two exceptions. Bridges and colleagues examined the efficacy of the Blizzard Blanket and Thermal Angel in preventing hypothermia under field conditions in a swine hemorrhagic shock model [4]. The Blizzard Survival Blanket (Blizzard Protection Systems, Manchester, UK) is a passive warming blanket made of reflexcell, a multilayer material designed to trap warm air decreasing convective heat loss, and a reflective surface to block radiant heat loss. The Thermal 
Angel (Estill Medical Technologies, Inc, Dallas, TX) is an in-line disposable, portable, battery operated intravenous warming device. They found the Blizzard Blanket alone provides some protection against hypothermia but does not prevent hypothermia. The Thermal Angel, when used in combination with the Blizzard Blanket, decreased the rate of heat loss and prevented the onset of hypothermia. However, weight and short battery life limit its use under field conditions.

In a similar study, Schmelz and colleagues investigated the effectiveness of Chillbuster (ChillBuster Blanket System model 8001; ThermoGear, Inc., Tigard, OR) and Chillbuster combined with a reflective blanket (ID:7210-00-935-6666, blanket, combat casualty lightweight, waterproof, aluminized plastic; Harris Manufacturing Co., Inc. Trenton, NJ) compared with a control group consisting of two wool blankets. The Chillbuster is a portable, electric/battery warming blanket. The Chillbuster only group had significantly lower core temperatures after $6 \mathrm{~h}$ compared with the Chillbuster with reflective blanket. After $6 \mathrm{~h}$ of cold exposure, the Chillbuster/reflective blanket group remained warm while the Chillbuster only and wool blanket groups developed hypothermia. These investigators emphasize that though the combined use of Chillbuster with a reflective blanket is effective, it has limitations. The electrical power requirements, weight and size, and other safety concerns of Chillbuster make it impractical for use in aeromedic transport. The Chillbuster is not currently approved by the US Air Force for in-flight use [13]. The use of the HEET, with and without inserts, should theoretically overcome many of the barriers associated with other hypothermia prevention devices. However, the results indicate neither HEET group was effective. While all groups became hypothermic, the wool blanket group was most effective in preventing loss of core body temperature. At the end of $6 \mathrm{~h}$, the HEET with thermal inserts (mean$=32.69^{\circ} \mathrm{C} \pm 1.5$ ) was only slightly more protective than HEET without thermal inserts (mean $=31.02^{\circ} \mathrm{C} \pm 1.8$ ). Notably, there was no statistically significant difference between the HEET groups $(P=0.248)$.

The reasons for the ineffectiveness of the HEET garments with and without heaters were related to conduction, convection, radiation, and evaporation. Conduction is the transfer of heat from a warmer object to a cooler object in direct contact with each other. Because the swine were placed on military litters elevated on stanchions, cool ambient air circulated underneath, leading to conductive heat loss from the animals. Convective heat loss occurs in response to movement of a fluid or gas. In this study, convection probably occurred when warm air next to the swine was displaced by the cool ambient air. The major factor contributing to the convective heat loss was the wind generated in the cooler, which circulated both over and under the litter. Radiation is the transfer of heat energy through an empty space. Radiation heat loss occurred primarily because of infrared emission from the warm body of the pig to the cooler ambient air. The HEET garments were not thick enough and did not provide enough insulation to prevent heat loss by conduction, convection, and radiation. The investigations theorized that the reflective inner layer lining in the HEET garment would transfer a significant portion of radiant heat back to the animal's body surface, and the air pocket within the garment would serve as an additional insulating layer. However, the garment was not effective, perhaps because there were not enough reflective properties, and there was limited air space between the pig and the blanket. Evaporation occurs when a liquid changes to a vapor. Although the addition of the heaters were slightly better in reducing heat loss compared with the HEET blanket alone, they were not effective. After $6 \mathrm{~h}$ in the cooler, the investigators removed the HEET blankets and found the heaters were still warm. The heat generated within the garment produced condensation, which in turn caused the top double-layer sheet covering the pigs to be wet. Consequently, the heat generated by the heaters was offset by evaporation. Although the use of two wool blankets was ineffective in preventing hypothermia, they were more effective in delaying the onset of hypothermia than the HEET garments with and without the heaters. The most probable reason that the wool blankets were more effective was that they were thicker than the HEET garments and trapped layers of air between the blankets, which provided more insulation from the cold ambient air.

\section{CONCLUSIONS}

The HEET garments with and without heaters are ineffective in preventing hypothermia. Based on the findings of this study, the investigators recommend the HEET garments not be used to prevent or treat hypothermia in operational environments. Further studies should be implemented to test the efficacy of other currently available thermal regulatory products for use in military and civilian healthcare.

\section{REFERENGES}

1. Holcomb J. Detrimental effects of hypothermia, point paper, consolidating medical assets. Military Reports 2005;1.

2. Marshall T, Jr.. Combat casualty care: The alpha surgical company experience during operation Iraqi freedom. Mil Med $2005 ; 170: 469$.

3. Moran D, Heled Y, Shani Y, et al. Hypothermia and local cold injuries in combat and non-combat situations-The Israeli experience. Aviat Space Environ Med 2003;74:281.

4. Bridges E, Schmelz J, Evers K. Efficacy of the blizzard blanket or blizzard blanket plus thermal angel in preventing hypothermia 
in a hemorrhagic shock victim (Sus scrofa) under operational conditions. Mil Med 2007;72:17.

5. Silbergleit R, Satz W, Lee D, et al. Hypothermia from realistic field resuscitation in a model of hemorrhagic shock. Ann Emerg Med 1998;31:339.

6. Kurz A, Sessler DI, Annadata R, et al. Midazolam minimally impairs thermoregulatory control. Anesth Analg 1995;81:393.

7. Giesbrecht GG, Bristow GK. Recent advances in hypothermia research. Ann NY Acad Sci 1997;813:663.

8. Arthurs Z, Cuadrado D, Beekley A, et al. The impact of hypothermia on trauma care at the 31st combat support hospital. Am J Surg 2006;191:610.
9. Leslie K, Sessler D. Perioperative hypothermia in the high-risk surgical patient. Best Pract Res Clin Anaesthesiol 2003;17:485.

10. Ianpietro P, Vaughan J, Goldman R. Heat production from shivering. J Appl Physiol 1960;15:632.

11. Dubick M, Brooks D, Macaitis J, et al. Evaluation of commercially available fluid-warming devices for use in forward surgical and combat areas. Mil Med 2005;170:76.

12. Holcomb J. Detrimental Effects of Hypothermia, Point Paper, Consolidating Medical Assets, Military Reports 2005;1.

13. Schmelz J, Bridges E, Wallace C, et al. Comparison of three strategies for preventing hypothermia in critically injured casualties during aeromedic evacuation. Mil Med 2007;172:322. 